\title{
O DIREITO À SAÚDE NO ESTADO DEMOCRÁTICO DE DIREITO BRASILEIRO
}

\author{
Angelita Maria Maders ${ }^{1}$
}

\section{RESUMO}

A compreensão da efetivação do Estado Democrático de Direito no Brasil passa por um estudo histórico-evolutivo do surgimento do Estado brasileiro, que se expressa de diversas formas e sob diferentes nomes. Se considerada a atual situação econômica, social, política e cultural do País, percebe-se que ainda existe um descompasso entre a Constituição formal e a garantia dos direitos por ela preconizados, já que o contrato social é constantemente violado pelo próprio Poder Público quando desrespeita os direitos fundamentais de seus cidadãos, em especial na área da saúde. O caos que se verifica no sistema de saúde pública demonstra que o País ainda está longe de alcançar o pleno exercício da democracia.

Palavras-chave: Constituição Federal. Direito à saúde. Efetividade. Estado Democrático de Direito. Evolução-histórica

\section{INTRODUÇÃO}

O problema vivenciado no sistema de saúde brasileira pode ser percebido diariamente não somente nos hospitais e postos de saúde, mas também junto ao Poder Judiciário, onde ingressam inúmeras ações judiciais, por meio das quais os cidadãos buscam haver a proteção de um direito constitucionalmente prescrito - a saúde. Por meio das referidas ações são solicitados medicamentos, cirurgias, exames clínicos e laboratoriais, dentre outros procedimentos na área médica e farmacêutica, os quais não lhes são fornecidos administrativamente, seja por falta do produto, seja por inexistência de previsão administrativa para tanto.

A crescente demanda judicial nessa seara enseja debates acirrados em diversos setores da Administração Pública, como também do Judiciário, inclusive no que toca a uma possível judicialização da política e de uma intervenção nas atribuições do Executivo. Sabe-se, contudo, que para a efetivação do Estado Democrático de Direito, o Estado deve iniciar a cumprir com as promessas feitas pelo Constituinte de 1988, que estabeleceu direitos na Constituição Federal e garantias para sua proteção. O que se percebe, hoje, é que, ante a inexistência de políticas públicas adequadas por parte do Executivo, o Judiciário acabou "assumindo" essa função.

A legitimidade do Judiciário, como dito, é questionada por diversos autores, assim como pelos administradores públicos, por entenderem que, em um regime democrático, tal atividade deveria ser típica dos representantes do povo, ou seja, do Executivo e do Legislativo, o que excluiria os Magistrado e, por sua vez, o Judiciário, uma vez considerada a forma de ingresso na carreira.

As discussões parecem estar longe do fim e a cada dia os Tribunais 
necessitam reafirmar sua posição no sentido da prevalência do direito fundamental à saúde, haja vista o aumento progressivo da demanda no setor e a aparente falta de estrutura, tanto do Executivo como do Judiciário para suportá-la.

Apesar da complexidade do tema e dos riscos que se corre em decorrência de uma simplificação, dadas as limitações deste estudo, o objetivo do presente artigo é realizar algumas reflexões para exaltar o debate acerca da questão da saúde pública no Brasil, sob um ângulo estritamente jurídico, mormente no que se refere à efetivação desse direito a todos, em igualdade de condições, rumo à perfectibilização do Estado Democrático de Direito.

\section{O DIREITO CONSTITUCIONAL À SAÚDE}

Antes de se adentrar no debate acerca da proteção do direito à saúde oportuno esclarecer em que consiste esse direito no ordenamento jurídico brasileiro. Nesse diapasão, não se pode olvidar que ele foi inserido em uma Constituição, pela primeira vez na história brasileira, na Constituição Federal de 1988, onde se encontra previsto em diversos dispositivos. Sua garantia é dever do Estado, nos termos expressos no artigo 196 da Constituição Federal. ${ }^{2}$

O direito à saúde é entendido como um direito social, assim como um direito fundamental, pois tem a ver com o direito à vida e à dignidade humana, tanto que é tratado como um direito "fundamentalíssimo" por Ingo Wolfgang Sarlet, que refere ser

[...] elementar que uma ordem jurídica constitucional que protege o direito à vida e assegura o direito à integridade física e corporal, evidentemente, também protege a saúde, já que onde esta não existe e não é assegurada, resta esvaziada a proteção prevista para a vida e a integridade física. ${ }^{3}$

Ocorre, contudo, que, apesar da proteção constitucional, o direito à saúde no Brasil encontra-se na enfermaria. As discussões acerca de sua efetivação plena vão desde a alegação da inviabilidade do Estado em cumprir com seu dever constitucional por falta de viabilidade econômico-orçamentária, até a questão da eficácia das normas constitucionais, já que alguns autores entendem, contrariamente ao disposto no artigo $5^{\circ}, \S 1^{\circ}$, da Carta Magna, que o direito à saúde trata-se de um direito que não tem eficácia plena e imediata, mas que depende da elaboração e do desenvolvimento de programas políticos para sua efetivação.

Contrariamente a tal entendimento, de se referir que o direito à saúde não é somente um direito fundamental da pessoa humana, como integra os denominados direitos de segunda dimensão, que marcaram a evolução do Estado de Direito para o modelo de Estado Constitucional, chamado de Estado Social, como forma de compensar as desigualdades sócio-econômicas reinantes na sociedade. ${ }^{4} \mathrm{~A}$ despeito de interpretações divergentes, de acordo com o disposto no artigo 5으 $\S$ 1으, da Constituição Federal, ele não depende de legislação infraconstitucional para ser concretizado. O próprio Supremo Tribunal Federal consagrou o direito à saúde como norma autoaplicável, cuja proteção deve ser equitativa e estendida a todos. 
Ao analisar a saúde no Brasil em seu aspecto histórico-evolutivo, com relação à própria evolução do Estado, Schwartz refere que ela também pode ser tida como um direito de terceira dimensão, por ser, além de um direito individual, também um direito social e, portanto, inerente à coletivadade - daí porque também considerada um direito difuso, transindividual. Além disso, o direito à saúde ainda pode ser entendido como um direito de quarta dimensão, se relacionado à engenharia genética. $^{5}$

Quando se trata da proteção dos direitos fundamentais, dentre estes a saúde pública, deve-se levar em consideração que, de acordo com 0 artigo 1ㅇ da Constituição Federal de $1988^{6}$, o Brasil é um Estado Democrático de Direito, e isso deve ter reflexos na elaboraão de sua legislação infraconstitucional. Além disso, deve-se ter em mente que o Brasil comprometeu-se com o bem-estar e a igualdade de seu povo no Preâmbulo da Constituição, nos artigos $3^{\circ}$, inciso IV, e 193, bem como com a garantia dos direitos humanos, que garanham status de direitos fundamentais no mesmo diploma legal, pelo que está vedado o retrocesso, especialmente no que tange ao exercício dos direitos fundamentais individuais e sociais.

Esses preceitos normativos, embora possam encontrar óbices burocráticos, econômico-financeiros, fiscais, são vinculantes e imperativos, tanto que cabe ao Estado e aos cidadãos respeitá-los e aos administradores torná-os reais. Mais, são princípios norteadores de toda a ordem jurídica, e, portanto, não podem ser tidos como meros programas de ação. ${ }^{7} \mathrm{~A}$ falta de verbas ou de recursos orçamentários não pode, pois, impedir o exercício desse direito, pois entre os valores postos em causa, devem prevalecer aqueles que tem a ver com a preservação da vida. Nesse sentido, de se referir que não se pode colocar preço na vida (precificação), tanto que não se tem como quantificar o valor (Wert) de uma vida com os gastos com medicamentos a serem empregados no restabelecimento da saúde do paciente.

O próprio Judiciário adotou posicionamento no sentido de que o direito à saúde como prestação positiva do Estado é perfeitamente exigível por meio de ações judiciais que são propostas para haver o fornecimento de medicamentos, internações hospitalares, cirurgias, dentre outros procedimentos médicos, tendo em vista a negativa do Poder Público em atender administrativamente a demanda existente.

No caso, tem-se ponderado que a ordem constitucional deve prevalecer para garantia dos direitos fundamentais quando em ponderação com os limites materiais e humanos, bem como de recursos, fatores estes que são arguidos pelo Poder Público como obstáculos ao atendimento de inúmeros casos, pois o bem maior que se encontra em jogo está diretamente ligado à própria proteção da vida, à dignidade humana. Questões de ordem econômica, política, devem, portanto, ceder diante da relevância do bem jurídico que se visa a proteger nas ações judiciais individuais que são propostas, pena de desmerecimento da própria cidadania, da democracia e, por sua vez, do Estado Democrático de Direito. 


\section{O ESTADO DE DIREITO: O ESTADO LIBERAL, O ESTADO SOCIAL E O ESTADO DEMOCRÁTICO}

É sabido que o surgimento do Estado e a sua organização até o estágio atual decorre de um processo evolutivo de longa data. Ele passou do Estado de Natureza ao Estado da Sociedade ${ }^{8}$, ao Estado Medieval até chegar ao chamado Estado Moderno, em sua primeira versão - absolutista (concentração do poder pelos soberanos). Para limitá-lo, a fórmula "consistia em colocar o homem acima do Estado, anterior a ele, através de uma combinação teórica entre contratualismo e direitos naturais do homem. Para formalizar tal inversão, surgiram as Constituições."

A segunda versão do Estado Moderno - o Estado Liberal -, por sua vez, está subdividida em Estado Legal e Estado de Direito. Dentro do Estado de Direito também há evoluções e diferenciações, que são denominadas de Estado Liberal de Direito, Estado Social de Direito e Estado Democrático de Direito.

O Estado de Direito é conceituado por Canotillho como "um Estado ou uma forma de organização político-estadual cuja actividade é determinada e limitada pelo direito". ${ }^{10}$ Diferencia-se do Estado de não-direito, porque neste o poder não possui limites jurídicos e aos cidadãos não são reconhecidos os direitos e liberdades protegidos pelo Direito. Segundo o referido autor, o Estado de não-direito caracteriza-se por decretar leis arbitrárias, cruéis e desumanas, em que há o exercício abusivo do poder e da força, deixando os cidadãos sem defesa jurídica eficaz; onde o direito identifica-se com a razão do Estado, ou seja, pela lei imposta por chefes, ou melhor, pela vontade do partido ou do governante, em nome do bem do povo; onde reina a injustiça e a desigualdade na aplicação do direito, já que imperam dois pesos e duas medidas na aplicação das leis, dependendo para quem devam ser impostas. ${ }^{11}$

O Estado de não-direito caracteriza-se, pois, pela identidade entre o direito e a força, no qual as leis devem ser obedecidas mesmo que representem a vontade política e arbitrária dos déspotas e desrespeitem os direitos e garantias fundamentais, inalienáveis, dos indivíduos e da coletividade. Como exemplos de um Estado de não direito pode-se citar os regimes nazi-fascistas, embora outros chegaram a denominá-los de "Estado de Direito Fascista", por entenderem que continham uma ordem legal. ${ }^{12}$

O Estado de Direito, ao contrário, pressupõe a existência dos princípios da separação dos poderes, a garantia dos direitos e liberdades, o pluralismo político e social, a subordinação do Estado à Constituição e o controle da constitucionalidade das leis. Ele visa a desenvolver-se fundado em princípios e valores que o conduzam a uma ordem justa e pacífica. Dentre esses princípios ou valores encontram-se a dignidade humana, a liberdade, a segurança, a igualdade, a vedação de práticas discriminatórias e a responsabilidade e responsabilização dos detentores ou titulares do poder, por isso é tida como uma ordem jurídica carregada de conteúdos, não apenas de formalismos. O Estado deve submeter-se à lei por ele criada, de modo que o poder político não é livre, mas vinculado, curvado ao Direito. Isso significa que 
o Estado, seus poderes locais e regionais, seus órgãos e agentes devem respeitar, observar, cumprir e fazer cumprir as normas jurídicas vigentes, assim como os particulares. Dessa feita, os governantes não estão acima das leis, e o Estado como um todo deve desenvolver suas atividades e desempenhar suas atribuições de acordo com os preceitos legais referentes à competência, à legalidade, à legitimidade. Outrossim, não basta que o Estado se submeta ao império da lei por ele positivada, mas deve estar informado e conformado por princípios e valores que estejam na consciência jurídica geral, pois as leis podem ser más, arbitrárias e injustas.

A opção pela forma jurídica do poder pressupõe que o Direito é o único meio legítimo de expressá-lo, razão pela qual seu exercício dá-se por intermédio de normas abstratas e gerais, permitindo a submissão ao Direito, alcançando-se o princípio da legalidade substancial. Para tanto, além da abstração e da generalidade, a norma deve ser originária da vontade geral, de modo a evitarem-se governos absolutistas ou autoritários disfarçados em Estado de Direito.

No processo de afirmação do Estado de Direito, a submissão do poder ao Direito vem acompanhada da exigência de que o poder se expresse por normas gerais e abstratas, já que os indivíduos postulam: "a) um tratamento geral e abstrato enquanto exigência de igualdade; b) a defesa perante a arbitrariedade que estaria ínsita na atuação do poder à margem do direito; e c) o incremento da segurança jurídica, dada a previsibilidade das ações do Estado". ${ }^{13}$

O Estado de Direito está, pois, vinculado ao Direito, ou seja, à Constituição, a uma ideia de justiça. $E$, em ele estando sujeito ao Direito, o poder político não é livre. Ao contrário, encontra limites na legislação, nas regras e princípios jurídicos vigentes e instituídos, de modo que aqueles que integram os órgãos públicos também devem obediência às normas jurídicas em vigor. Além disso, em o poder estando vinculado ao Direito, seu exercício pelo Estado somente poderá ocorrer ou efetivar-se por meio de instrumentos previamente institucionalizados pela ordem jurídica e por aqueles que detêm competência legal para praticá-lo.

Outrossim, quando se relaciona o Estado à ideia de justiça, está-se a referir à subordinação aos pressupostos axiológicos previstos na Constituição, de forma a coibir abusos que possam advir do próprio Estado no que tange à criação de normas jurídicas ou de sua aplicação ao caso concreto. Por isso, as leis devem estar adstritas à legitimidade, à ideia material de justiça, pena de tornarem-se abusivas e não merecerem respeito e obediência.

Sob outro ângulo, o Estado de Direito deve primar pelos direitos fundamentais, pois estes constituem a "base de sua fundamentação e de sua legitimidade políticojurídica". ${ }^{14}$ Por tal razão, os direitos e garantias fundamentais dos cidadãos legitimam a ordem jurídica, de modo a estarem no topo da pirâmide hierárquica das normas, fazendo com que o legislador, o Estado e quem quer que seja, respeitemnos.

Uma outra dimensão do Estado de Direito é aquela que garante o acesso ao Judiciário caso houver violação ou ameaça de violação a direitos dos cidadãos. Aliados a essa garantia estão os princípios do contraditório, da ampla defesa, da 
igualdade material entre as partes no processo, da assistência judicial ou jurídica gratuita e integral a todos os necessitados economicamente. $\mathrm{E}$, em sendo o Estado de Direito o garantidor do acesso à justiça, deve proporcionar segurança e confiança aos administrados quanto à aplicação da lei. Desse modo, para a realização do Estado de Direito deve haver

[...] um Estado subordinado ao direito, que defende os direitos fundamentais e a segurança de seus cidadãos e que tem por base o princípio da razoabilidade, da responsabilidade por seus atos e do respeito da via judicial. Além disso, estrutura-se a partir da divisão dos poderes e da descentralização de suas atividades, sendo a sua administração orientada pelo princípio da legalidade e voltada à supremacia dos princípios da liberdade e da igualdade, sem nunca afastar o fundamento popular do poder e a defesa do bem público. ${ }^{15}$

O Estado de Direito não pode, pois, ser considerado somente sob o aspecto formal da limitação técnica do poder, mas como uma concepção acerca da democracia, da liberdade e do próprio papel do Estado em efetivá-los. Assim, ele pode apresentar-se como liberal, social ou democrático, de acordo com seu conteúdo.

O Estado Liberal caracteriza-se pela ideia de limites com relação aos poderes do Estado, bem como com relação a suas funções, embora a definição de liberalismo seja complexa em face das transformações ocorridas em sua história. A teoria do contrato social prevê a limitação e a legitimação do poder na Constituição, sendo esta uma das reivindicações dos movimentos revolucionários e do pensamento liberal da época. Assim sendo, a conceituação do liberalismo e do modelo liberal são difíceis, já que sofrem a influência do tempo e do local onde são empregados, bem como do pensamento de quem os define.

Ele apresenta como características fundamentais que o definem as seguintes:

a) Separação entre Estado e Sociedade Civil mediada pelo Direito, este
visto como ideal de justiça.
b) A garantia das liberdades individuais; os direitos do homem aparecendo
como mediadores das relaçães entre os indivíduos e o Estado.
c) A democracia surge vinculada ao ideário da soberania da nação
produzido pela Revolução Francesa, implicando a aceitação da origem
consensual do Estado, o que aponta para a idéia de representação,
posteriormente matizada por mecanismos de democracia semidireta -
referendum e plebiscito - bem como, para a imposição de um controle
hierárquico da produção legislativa através do controle de
constitucionalidade.
d) O Estado tem um papel reduzido, apresentando-se como Estado Mínimo,
assegurando, assim, a liberdade de atuação dos indivíduos.

Isso não quer dizer que o Estado Liberal seja alheio ao conteúdo jurídico do Estado, pois, se assim fosse, haveria um esvaziamento de seu conteúdo liberal, que levaria a um positivismo jurídico preponderante, ou seja, à identificação do Direito somente com a lei, e o Estado a um Estado Legal, sem qualquer cunho de ordem material, substancial. O Estado Liberal de Direito não pode, portanto, ser visto 
somente sob o aspecto formal - relativo à legalidade -, mas deve ser analisado sob o conceito material, que diz respeito ao conteúdo da atividade estatal, da relação do Estado com seus cidadãos, de modo a assegurar as pretensões individuais frente à atuação estatal.

Em decorrência, no entanto, de o liberalismo puro pregar uma "teoria antiestado", privilegiando o individualismo, a partir de 1880 , foi surgindo um novo pensamento liberal - creditado aos democratas radicais ${ }^{17}$-, já que o modelo individualista não se adequava à nova realidade econômica vigente, principalmente no setor industrial. Para tanto, a função do Estado, que era meramente para a segurança individual, restou ampliada para ser o "removedor de obstáculos para o autodesenvolvimento dos homens". ${ }^{18}$ Com a ampliação da atuação estatal reduziuse a atividade livre do homem, teoria sustentada pelo Estado Mínimo.

Nas primeiras décadas do Século XX, o Estado Liberal de Direito entrou em crise fazendo surgir o modelo constitucional de Estado, isso em virtude do desvio do modelo liberal da praxis econômica e social, do conflito entre a realidade social e da não-neutralidade do Direito com respeito aos conflitos sociais. ${ }^{19}$ Para tanto, é revista a eficácia do Direito como limitação do poder, redimensionando a legalidade vigente.

Com a passagem do Estado Liberal de Direito ao Estado Constitucional, as Constituições ganharam caráter normativo superior e vinculante, implicando, ainda, uma atuação mais politizada do que neutra por parte dos juristas, muito mais regida por princípios do que por normas. Em decorrência dessas mudanças ocorridas na sociedade e das próprias ideias liberais, um novo conceito de Estado de Direito foise formando e expandindo, trazendo em seu bojo valores e objetivos de cunho social, os quais foram acrescidos ao modelo de Estado Liberal de Direito existente para dar origem ao Estado Social de Direito. Esse cunho social consiste na inclusão de novos direitos para limitar a atuação estatal, bem como na efetiva atuação ou prestação do Estado em prol de seus administrados, concedendo-lhes garantias coletivas. $^{20}$

A construção desse modelo de Estado não ocorreu de forma repentina, já que está vinculada a um processo histórico de longa data, pois tem acompanhado o "projeto liberal transformado em Estado de Bem-Estar Social no transcurso da primeira metade do século XX e que ganha contornos definitivos após a Segunda Guerra Mundial". ${ }^{21}$ Essa passagem está marcada e ligada aos movimentos operários na conquista da regulamentação de seus direitos, principalmente daqueles referentes às relações de produção, mais precisamente à redução da jornada de trabalho para oito horas diárias, aos benefícios previdenciários, à assistência social, à moradia, ao transporte, à salubridade....

Em virtude de questões dessa ordem, o Estado, que antes tinha como função básica garantir o livre desenvolvimento das relações sociais no âmbito do mercado econômico, passou a assumir funções que eram próprias dos particulares ou do setor privado, como garantidor dos benefícios sociais aos indivíduos. No decorrer da expansão do Estado Social, a atuação assistencial que passou a ser realizada pelo ente estatal deixou de ter um caráter caritativo para ser tida como um direito político próprio da cidadania, vinculado ao princípio da dignidade da pessoa humana, e dever do Estado em garanti-lo para cumprir com sua função social. Dessarte, o 
Estado de Bem-Estar Social é aquele no qual os cidadãos, independentemente de sua posição ou situação social, tenham seus direitos protegidos por meio de instrumentos e prestações públicas contra abusos ou dependências, de modo que o princípio da igualdade substancial aparece como alicerce da atuação interventiva por parte da Administração Pública. Mas esse Estado possui um viés mutante muito grande, pois sujeito às transformações sociais, embora mantenha seu sentido próprio - o de garantir a sua função social.

Quando assume a forma democrática, o Estado de Direito objetiva a igualdade de maneira a não somente limitar a ação estatal para evitar abusos, mas para transformar a comunidade. A lei, no Estado Democrático de Direito, não é mais tida com um caráter de sanção ou promoção, mas de re-estruturação das relações sociais. Por isso se diz que o Estado Democrático de Direito agrega novas características ao núcleo liberal acrescido da questão social, pois visa a efetivar a igualdade substancial dos cidadãos, garantindo-lhes condições mínimas de vida. Também dá valia ao projeto de solidariedade, de caráter comunitário, onde o personagem principal é a coletividade difusa. A lei, por sua vez, é mecanismo de transformação social, de modo a manter o espaço vital da humanidade. E, em assim sendo, o Estado Democrático de Direito é um "plus normativo" em relação ao Estado liberal e ao Estado social, pois impõe ao ordenamento jurídico e à ação estatal o conteúdo de transformação da realidade, baseado na constitucionalidade, em um sistema de direitos fundamentais individuais e coletivos, na igualdade, na legalidade e na justiça social.

No Estado Democrático de Direito há, pois, um aumento dos direitos e, principalmente, uma transformação no conteúdo deste para a promoção da sociedade e da democracia, voltada ao caso concreto, de modo a sair do formalismo jurídico para a concepção material de justiça, para tornar-se um Estado de Direito substancial.

Com isso, no entanto, desloca-se grande esfera de tensão social do Executivo para o Judiciário, que acaba tendo de interferir para garantir a efetividade dos direitos constitucionalmente previstos e a própria democracia e seus fundamentos, como vem ocorrendo no Brasil no que se refere ao direito à saúde.

\section{O ESTADO DEMOCRÁTICO DE DIREITO NO BRASIL}

O Estado brasileiro é de criação recente e tem como base os ideários e modelos europeus. Ele tem como característica tomar frente nas suas relações com a sociedade, em face da falta de maturidade política da população e da pouca abertura de espaço para mobilização da comunidade por parte dos "donos do poder", interessados em manter a sociedade dividida, dependente e fácil de ser controlada. Para tanto, as elites dominantes utilizam-se, muitas vezes, do Estado para manterem e resguardarem seus interesses e privilégios, impondo uma visão do Estado como implementador da liberdade, dos direitos dos cidadãos, do único capaz de garantir a segurança, o desenvolvimento e a justiça social, escondendo seu verdadeiro objetivo - servir às finalidades dos grupos que dispõem do poder. Isso favorece o clientelismo, o apadrinhamento, o nepotismo, o coronelismo, a malandragem e "as irregularidades e desvios no padrão cultural de comportamento 
do homem brasileiro." ${ }^{22}$ Por outro lado, a população não tem forças para se organizar, pois está dividida, esperando uma atuação ativa "paternalista" do Estado.

Aliado a tal fator, não se pode negar a existência de administrações corruptas, voltadas para a garantia e defesa dos interesses da classe dominante, motivo pelo qual questiona-se se, efetivamente, encontra-se implantado o Estado Democrático Brasileiro. Abstraindo a questão brasileira, Nietzsche já criticava o Estado quando referia que ele significava a morte dos povos. ${ }^{23}$

Como corrigir tal situação e mudar a sociedade, de modo a torná-la mais madura, participativa e democrática? Essa questão aflige a muitos e uma resposta parece evidente para Wolkmer: "não basta eliminar as elites dominantes e o tipo tradicional de Estado se não ocorrer uma alteração na mentalidade e no comportamento das pessoas."24

A promulgação da Constituição Federal de 1988, marco da democracia brasileira, pelo menos no plano teórico, é considerada um avanço na formação do Estado brasileiro, pois ela apresenta o Estado como sendo de Direito, tendo como fundamentos a cidadania, o pluralismo político e a dignidade da pessoa humana, além de denominá-lo um Estado Democrático de Direito no seu artigo primeiro.

A versão brasileira de Estado de Direito, em especial na sua modalidade democrática, segue, no entanto, duramente criticada, pelo fato de que as leis deveriam ser elaboradas por seus verdadeiros legitimados - o povo (que parece preferir estar alheio a isso) - e não por representantes legais, que sequer elegem como prioridade a vontade popular ao elaborarem lei, a fim de diminuir a desigualdade social e a injustiça. Ela segue criticada, também, em virtude de que, em um Estado Democrático de Direito, não necessariamente há justiça, pois a sociedade somente pode ser considerada justa se a questão da justiça permanecer aberta constantemente, conforme refere Costariadis, já que a democracia é uma criação abstrata e ininterrupta de novos direitos, onde o regime político considera 0 conflito legítimo, instituindo-o como um direito de cidadania. ${ }^{25}$

Por isso, o Estado de Direito somente se aproximará do Estado de Justiça, de justiça social, de justiça sanitária, se incorporar às suas leis formais princípios e valores substanciais, dando-Ihes vida prática, de modo a poder aferir a natureza justa ou injusta das instituições, das leis, dos comportamentos.

O princípio da igualdade, por exemplo, é um princípio de justiça que deve ser feito valer na prática, pois a democratização das relações da sociedade implica o aumento da demanda e da atividade estatal, e, em consequência há um aumento da burocracia. $O$ aumento da atividade estatal, em especial na efetivação dos direitos sociais, por sua vez, faz crescer os gastos e o deficit público. Esse deficit resta ampliado pelas crises econômicas que assolam a humanidade, tanto que, para superar os problemas, constantemente aumenta-se a carga tributária e fiscal e reduz-se custos através da diminuição da ação do Estado. Aliadas a tais fatores, novas crises são desencadeadas, dentre elas a crise ideológica entre a democratização do acesso e a burocratização do atendimento. ${ }^{26}$

Na esteira da Constituição brasileira, para efetivar-se a democracia, garantir a 
dignidade da pessoa humana e diminuir o abismo entre aqueles que se encontram em situação de inferioridade econômica e social em face daqueles que dispõe de maiores recursos financeiros, foram elaborados, então, inúmeros diplomas legais, especialmente no âmbito da tutela de direitos coletivos. Vê-se que o Estado, após uma longa evolução histórica, assumiu uma postura ativa e mais protetiva para a garantia da igualdade substancial. Ocorre que muitas delas existem apenas no âmbito teórico, o que ensejou um aumento das atribuições do Poder Judiciário para implementar a justiça e aplicar as leis de acordo com os casos concretos, deixando de lado posicionamentos positivista-normativos para adequar a norma à realidade social cada vez mais complexa.

\section{O DIREITO À SAÚde NO ESTADO DEMOCRÁtICO DE DIREITO BRASILEIRO}

Apesar de a Constituição Federal de 1988 trazer em seu bojo não somente direitos, mas também mecanismos de garantia desses direitos, ainda existe um descompasso entre a teoria formal e a prática (material), pois a proteção de alguns direitos fundamentais ainda é privilégio de uma parcela minoritária da população, que dispõe de recursos para arcar com as despesas para usufruir dos serviços e dos meios adequados ao seu exercício na esfera privada ou daqueles que efetivamente conhecem seus direitos.

O texto constitucional apresenta um rol exemplificativo de direitos dos cidadãos, sejam eles individuais ou sociais fundamentais, o que the rendeu o nome de "Constituição Cidadã". Ocorre, no entanto, que os referidos direitos não se encontram efetivados em sua plenitude no mundo dos fatos, em especial quanto aos últimos, dentre os quais está o direito à saúde, seja por falta de políticas públicas para tanto, seja por desconhecimento dos próprios brasileiros. Considerando tal situação e o já constatado "caos na área sanitária", um simples exercício de imaginação conduz o leitor a algo mais dramático, se pensada a questão da garantia do direito à moradia, ao lazer, também previstos no artigo $6^{\circ}$ da Constituição Federal. $^{27}$

Se analisada a questão da saúde pública sob a concepção jurídico-formalista vigente com relação à divisão das funções de poder e ou repartição de competência entre os integrantes da Federação, não caberia ao Judiciário o exercício de outras atividades que são típicas das demais funções de poder, pena de uma ingerência desmedida e ferimento do princípio da separação dos poderes preconizados na Constituição Federal. Uma vez adotada essa concepção de Estado, não caberia ao Judiciário a elaboração de políticas públicas e sua aplicação prática em prol dos administrados, já que estas competem ao Legislativo e ao Executivo. O que fazer, no entanto, quando aqueles que deveriam elaborar e executar referidos programas não o fazem ou o fazem de modo insatisfatório?

Quando se trata da saúde pública, não resta alternativa àqueles que se veem privados dos meios necessários ao exercício de seus direitos fundamentais a não ser o Judiciário. Este, por seu turno, se não julgar de acordo com o regramento constitucional, não pode ser mantido por não cumprir com sua missão institucional, já que, na elaboração do artigo 196 da Constituição Federal, o Constituinte 
certamente objetivava que nenhum brasileiro morresse por falta de saúde.

Em face dessa realidade, a função dos Magistrados acabou sendo ampliada, já que, como dito, não se pode deixar de dar uma solução às demandas que lhe são postas, as quais são cada vez mais abrangentes e complexas, de matizes tão diversas e envolventes, que abarcam, inclusive, decisões políticas. Considerando que aos Juízes cabe assegurar o disposto na Constituição Federal, não podem olvidar que dentro dela estão os direitos e garantias individuais e os direitos sociais.

A teoria de Montesquieu, portanto, tem sido, em decorrência da complexidade das relações, mitigada, tanto que o que se tem é uma participação efetiva do Judiciário na realização da democracia, com a garantia in concreto dos direitos dos cidadãos. Ocorre, no entanto, que o rumo das coisas tem demonstrado que, se os casos forem sendo resolvidos, um a um, o próprio sistema judicial não suportará a demanda, por total falta de estrutura para tanto, tanto que Luhman já havia concluído o Judiciário não tem condições de suportar a política. ${ }^{28}$

Essa superação do modelo tradicional de separação dos poderes e a ampliação das funções do Judiciário, com sua intervenção na política, acabou ensejando um fenômeno denominado entre os teóricos de "judicialização da política". Segundo eles, em um sistema democrático constitucional, a judicialização da política se justifica e encontra fundamento na própria superioridade da Constituição, que deve ser mantida íntegra e respeitada. Com esse papel mais participativo do Judiciário está-se preservando o núcleo dos direitos, isto é, resguardando os princípios e fundamentos da própria democracia.

Para outros autores, para se atingir uma reforma social, esse sistema, que amplia as atribuições judiciais, é falho, pois poderia implicar a destinação de recursos em uma área com igual ou menor necessidade do que outros setores e, por isso, geraria um desequilíbrio nos gastos públicos. ${ }^{29}$ Há pois, correntes que defendem um Judiciário com poderes limitados. Para elas, os tribunais têm menos condições do que os canais políticos para deliberar acerca de reformas sociais, por essa razão não poderiam condenar o Poder Público ao fornecimento de medicamentos a pessoas individualizadas, por exemplo.

De acordo com os autores que defendem esse posicionamento, não se poderia chegar ao extremo de tornar o juiz e a lei as únicas referências para os indivíduos; deveria-se, ao contrário, criar novos canais comunicativos, que atribuiriam aos cidadãos a autoria do Direito, e isso seria mais eficiente para a consagração do poder democrático do povo. ${ }^{30}$ Para essa corrente de entendimento, a ideia de judicialização da política deve ser rejeitada. Segundo ela, o Judiciário deve ser forte e estratégico para a democracia, garantindo os procedimentos para a deliberação democrática, não o conteúdo do que seria decidido, pois a decisão quanto a esse compete ao povo. Além disso, há aqueles que defendem que, embora a saúde seja um direito social fundamental, não constitui um direito subjetivo a qualquer prestação estatal para sua proteção e preservação. ${ }^{31}$

Posição contrária é aquela que defende um Judiciário mais participativo na guarda dos princípios e valores democráticos, como um instrumento de transformação social, com um trabalho efetivo na prevenção dos conflitos. Para isso, 
por óbvio, o Judiciário não pode permanecer exercendo ou adotar um papel passivo na democracia contemporânea. Deve, todavia, pautar sua atuação em princípios de natureza jurídica, não em política. Dworkin rejeita esse papel passivo do Judiciário em sua obra $O$ Império do Direito, mas também não designa um papel ativista aos Magistrados. Para o referido autor, um Juiz passivista anula os atos dos demais poderes constituídos, enquanto que o ativista o faz sempre que desaprova qualquer ato dos demais. ${ }^{32}$

Ocorre, no entanto, que a democracia não é perfeita e para corrigir suas imperfeições, acaba-se, inevitavelmente, transferindo algumas atribuições do Executivo e do Legislativo ao Judiciário, em especial quando se está a tratar dos direitos das minorias excluídas. Com isso, acaba-se conferindo-lhe poderes políticos e, de certo modo, beneficiando os pobres e as minorias esquecidas na democracia da maioria, até mesmo porque a elas é viabilizado o acesso à justiça.

Se há um tempo se falava do Executivo como o "poder principal", hoje pode-se dizer que a sociedade vive a "era do Judiciário", pois o Supremo Tribunal Federal tem poderes para anular as decisões de outros setores que forem contrárias à Constituição Federal. Pode-se dizer, então, que os tribunais têm um importante papel na construção da democracia.

Nesse diapasão, não se pode esquecer que a saúde é uma das dimensões do mínimo existencial à dignidade da vida humana, pois ela é condição de possibilidade da última ${ }^{33}$ e, portanto, da democracia. As normas que tratam da saúde pública, seja ela considerada uma direito individual ou social fundamental, devem ser interpretadas de acordo com o princípio da dignidade humana. Por isso, segundo Dworkin, as decisões judiciais devem ser pautadas em princípios jurídicos e não em políticas de promoção do bem-estar social, pois o Judiciário tem por "função garantir os direitos individuais e não assinalar objetivos sociais." ${ }^{34}$ Estes já foram definidos pelo Poder Constituinte Originário. Basta o Executivo cumpri-los.

Ao tratar do dever público para alcançar os meios necessários à proteção da saúde, Leal refere que é necessário ter em conta os critérios utilizados para determinar quem efetivamente necessita do auxílio estatal nesse aspecto, bem como quem é responsável por tal mister. ${ }^{35}$

No que se refere à primeira, considerando as disposições axiológicoconstitucionais, de se referir que abrange e se dirige a todos, como expresso no artigo 196 da CF, de modo que inexiste um rol de possíveis beneficiários. Não cabe ao Executivo ou ao Judiciário restringir o acesso somente aos necessitados, aos portadores de doenças graves, aos idosos, etc., pena de fazer-se restrições que a Carta Magna não fez. Por isso, a Administração Pública deve adotar critérios razoáveis para atender a demanda social, não somente aquela já inscrita em seus programas, mas visando à verdadeira demanda universal existente.

O que se verifica, na atualidade, lamentavelmente, é que os projetos e programas sociais desenvolvidos não contemplam a todos em igualdade de condições, nem mesmo as peculiaridades dos casos, de modo que estes acabam tendo de ser resolvidos pelo Judiciário. 
Quando isso ocorre, a satisfação do problema individual posto a julgamento, pode, segundo a tese do ente público, inviabilizar o deferimento de outros pedidos. Ocorre, entretanto, que o Estado não logrou provar, em nenhuma das ações judiciais, por meio de cálculos orçamentários, que não dispõe de recursos para fazêlo. Ademais, ele não tem, também, como eximir-se de sua responsabilidade, a qual é comum de todos os entes da Federação. Em casos dessa ordem, deve-se, por certo, ponderar os valores postos em causa utilizando-se o princípio da proporcionalidade e da razoabilidade. Não pode, pois, o Poder Público, em nome da reserva do possível, negar as condições mínimas de existência digna a seus cidadãos.

Quanto à responsabilidade pelo fornecimento dos meios à proteção e preservação da saúde dos cidadãos, é pacífica nos tribunais a responsabilidade solidária de todos os entes da Federação. Além disso, os protocolos e as portarias administrativas de divisão das atribuições não têm o condão de mitigar direitos fundamentais, fruto de elaboração legislativa decorrente do Poder Constituinte Originário, pois ferem o disposto no parágrafo único do artigo $1^{\circ}$ da $C F$, já que não são elaborados por representantes do povo.

Isso conduz à comprovação de que o Estado Democrático de Direito ainda não se encontra corporificado na sociedade brasileira, até mesmo porque ele não consegue cumprir com suas atribuições na efetivação dos direitos fundamentais e sociais a que se obrigou na Constituição Federal, tarefa esta que hoje acaba tendo de ser exigida judicialmente por meio de ações autônomas para haver a condenação do Poder Público à prestação de ações na área da saúde, que deveria executar administrativamente.

Por isso se diz que para a proteção dos direitos, para a perfectibilização da democracia, não basta a existência de uma Constituição. É preciso mais; isto é, é necessária uma Constituição forte, que enseja respeito e confiança em suas normas, na sua observância por todos, dentre eles, o próprio Estado. Para tanto, além de uma Constituição formal, deve haver o elemento subjetivo, ou seja, o sentimento de confiança na Constituição, pois na fé que o povo deposita em sua Constituição é que se pode manter um sistema democrático e preservar-se os direitos dos cidadãos e também um Judiciário forte para fazer valer as disposições constitucionais.

Outrossim, deve-se combater o desequilíbrio entre o aumento da consciência de ter direitos e a capacidade das instituições públicas em garanti-los. Por isso,

[...] se uma cultura elementar de direito é necessária a todos os cidadãos a fim de que possam colaborar com a ordem social, eles devem saber assim mesmo que, também nesse campo, como em todo outro, a necessidade resolve-se na insuficiência. Se o direito é um instrumento da justiça, nem a técnica nem a ciência bastam para saber manejá-lo. Infelizmente, a ilusão de sua suficiência tem raízes profundas na alma humana e não é fácil desarraigá-la; mas qualquer um de nós tem o dever de fazer o quanto puder para alcançar esse objetivo. Exatamente os ramos, quando tiveram de definir o jurisconsulto, disseram, antes de tudo: vir bonus. Sem a bondade, a ciência do direito poderá, sem dúvida, fazer que cresça a árvore do direito, mas essa árvore não dará os frutos de que os homens têm necessidade. ${ }^{36}$ 
Vê-se, pois, que a saúde, assim como os demais direitos, estão vinculados à própria organização e administração do Estado e estes estão envoltos em mecanismos e relações cada vez mais complexas e a exigir novas e melhores posturas. Para tanto, deve-se privilegiar a adequação da atuação das políticas públicas à realidade normativa, não somente na área da saúde, mas em todos os sentidos para preservar os direitos fundamentais.

Preservando o direito à saúde está-se, por sua vez, garantindo o exercício da cidadania, pois o próprio direito à saúde com um direito fundamental social representa a passagem do Estado Liberal ao Estado Social e, por sua vez, ao Estado Democrático.

\section{CONCLUSÃO}

Definir o Estado brasileiro, no contexto atual, é tarefa árdua, pois o contrato social firmado é constantemente violado pelo Poder Público quando a vida de seus cidadãos é comprometida pelas políticas adotadas, quando a lei (instrumento de garantia da liberdade) sofre de vícios com relação a sua legitimidade, pela falta de representação dos legítimos interesses da coletividade, quando os direitos fundamentais não são respeitados, fazendo crer que houve um retorno à barbárie.

Apesar de o Estado Democrático de Direito ser de fundamental importância para a proteção efetiva dos direitos à saúde, a prestação dos serviços na área sanitária no Brasil enfrenta diversos problemas, pois não atinge a todos em igualdade de condições e, em muitos casos, com a eficiência almejada. Parece que os administradores públicos esquecem que, em um Estado de viés democrático, os direitos fundamentais são considerados vetores e valores superiores e intervêm na configuração e na identificação do próprio poder democrático. Por isso, a proteção do direito à saúde e, por sua vez, a busca pela qualidade de vida, é um compromisso de todos e assim deve ser levado em consideração ao serem elaboradas as políticas públicas para seu desenvolvimento prático.

Nesse passo, de se mencionar que a saúde está vinculada à vida, a uma vida digna, como já contemplado no artigo 25 da Declaração dos Direitos do Homem da Organização das Nações Unidas, à cidadania plena, ao desenvolviemtno do país, à dignidade humana. Sabe-se, no entanto, que uma solução ao problema sanitário no País não se alcança apenas com a existência de leis, tanto que não se resolverá tão-somente no plano jurídico com a exigibilidade do cumprimento da norma perante o Judiciário, mas deve ser encontrada por meio de uma melhor política para proteção dos direitos na esfera pública, por meio de uma atuação conjunta entre o Poder Público e a sociedade.

O que se percebe, porém, é que a perfectibilização da democracia no Estado de Direito brasileiro ainda está longe de ocorrer, se considerados os diversos problemas e paradoxos que se verificam diariamente em diversos setores da política, da economia, da saúde pública, da educação, dentre outros. Por isso, no presente artigo, a questão da efetivação do direito à saúde foi utilizada para demonstrar que, na prática, o preconizado Estado Democrático de Direito inexiste em sua forma plena, já que, no contexto histórico evolutivo apresentado, esse 
Estado assumiu um papel de suma importância na proteção do ser humano e na transformação da sociedade para torná-la mais justa e igualitária, mas os compromissos assumidos não têm sido cumpridos.

Ocorre, no entanto, que no contexto atual, não há mais como se conceber a questão da saúde sem a figura do Estado, a quem os menos favorecidos economicamente devem recorrer em razão do dever assumido pelo primeiro em prestar a assistência necessária e, consequentemente, primar pela efetivação da igualdade substancial, nos moldes escritos na Constituição Federal.

Embora se espere desse Estado que ele paute suas políticas públicas em favor de assegurar aos cidadãos o direito ao desenvolvimento de garantias que deem condições dignas de igualdade, muito resta a ser feito para, efetivamente, garantir a todos os cidadãos o exercício pleno do direito à saúde, ainda mais quando se sabe que a maioria dos brasileiros depende do Sistema Único de Saúde, que apresenta falhas em sua organização e funcionamento.

Tem-se que o Estado, ao não criar condições necessárias e adequadas ao exercício do direito à saúde, não está atendendo aos preceitos estabelecidos na Constituição Federal. Para alterar essa situação, é necessário repensar o sistema de saúde pública no Brasil. Para tanto, uma alteração do pensamento, de paradigmas faz-se necessária, bem como a implementação de políticas públicas verdadeiramente voltadas aos cidadãos, pois, somente uma visão do Direito de acordo com a realidade social pode impedir a desagregação do povo. Esse deve ser o ideário do Estado Democrático de Direito, onde o elemento principal é o cidadão, e a lei mecanismo de transformação da sociedade.

Descortina-se, desse modo, que é necessário investir para materializar ou colocar em prática os instrumentos de proteção dos direitos dispostos formalmente no ordenamento jurídico, sob pena de nunca se alcançar o Estado de Direito, muito menos o Estado Democrático de Direito (tão almejado), no qual a lei deve ser um mecanismo de defesa das pessoas frente às adversidades e de transformação da sociedade para garantir uma vida com um mínimo de qualidade a seus integrantes.

Deveras, deve-se ter presente que a dignidade da pessoa humana deve estar vinculada à afirmação e à exigência de direitos de uma pessoa frente às outras ou ao próprio Estado, em especial na área sanitária, pois o direito à saúde tem a ver com o direito à vida, à uma vida com um mínimo de dignidade. Por isso, pode-se ir além e mencionar que, tão-somente a existência do Estado, na forma legal estrita, não é necessária para que sejam garantidos os direitos fundamentais dos cidadãos. É preciso, antes de tudo, um regime político adequado, pois somente a verdadeira democracia representativa e pluralista, em um Estado de Direito, pode propiciar um sistema de direitos fundamentais.

\section{THE RIGHT TO HEALTH IN THE DEMOCRATIC STATE OF BRAZILIAN}

\section{ABSTRACT}


The understanding the effectiveness of the democratic rule of law in Brazil is going through a historical study of the evolution of the Brazilian state, which is expressed in various forms and under different names. When comparing the current economic, social, political and cultural life of the country, one realizes that there is still a gap between the formal constitution and guarantee the rights envisaged by it, as the social contract is constantly violated by the government itself when it disregarded the basic rights of its citizens, especially in health. The chaos that exists in the public health system shows that the country is still far from achieving the full exercise of democracy.

Keywords: Constitution. Democratic state. Effectiveness. Historical evolution. The right to health. The right to health.

\section{NOTAS}

1 Defensora Pública. Mestre em Gestão, Desenvolvimento e Cidadania pela UNIJUí. Doutora em Direito pela Universidade de OSNABRÜCK, Alemanha. Professora do Mestrado em Direito da URI e professora nos Cursos de Graduação da URI e da UNIJUÍ. E-mail: angmaders@hotmail.com. Endereço: Governo do Estado do Rio Grande do Sul, Avenida Venâncio Aires, Centro - CEP 98801-590 - Santo Ângelo, RS - Brasil.

2 Art. 196. A saúde é direito de todos e dever do Estado, garantido mediante políticas sociais e econômicas que visem à redução do risco de doença e de outros agravos e ao acesso universal e igualitário às ações e serviços para sua promoção, proteção e recuperação.

3 SARLET, Ingo Wolfgang. Algumas considerações em torno do conteúdo, eficácia e efetividade do direito à saúde na Constituição de 1988. Salvador: Revista Diálogo Jurídico no 10, jan. 2002. p. 3.

4 SARLET, Ingo Wolfgang. Algumas considerações em torno do conteúdo, eficácia e efetividade do direito à saúde na Constituição de 1988. Salvador: Revista Diálogo Jurídico no 10, jan. 2002. p. 7.

5 SCHWARTZ. Germano. (Org.). A saúde sob os cuidados do direito. Passo Fundo, UPF, 2003. p. 119.

6 Art. 1 A República Federativa do Brasil, formada pela união indissolúvel dos Estados e Municípios e do Distrito Federal, constitui-se em Estado Democrático de Direito e tem como fundamentos:

I - a soberania;

II - a cidadania;

III - a dignidade da pessoa humana;

IV - os valores sociais do trabalho e da livre iniciativa;

$\mathrm{V}$ - o pluralismo político.

Parágrafo único. Todo o poder emana do povo, que o exerce por meio de representantes eleitos ou diretamente, nos termos desta Constituição.

7 Esse também é o posicionamento que se extrai do texto Eficácia e aplicabilidade das normas constitucionais sobre direitos sociais de José Afonso da Silva, 26 páginas, mimeografado.

8 STRECK, Lênio Luiz; MORAIS, José Luís Bolzan de. Ciência Política e Teoria Geral do Estado. Porto Alegre, Livraria do Advogado, 2000. p. 36.

9 CORRÊA, Darcísio. A Construção da Cidadania - reflexões histórico-políticas. ljuí: Unijuí, 2000.

10 CANOTILHO, J.J. Gomes. Estado de Direito. Lisboa: Gradiva - Cadernos Democráticos, 1999b, p. 12.

11 CANOTILHO, J.J. Gomes. Estado de Direito. Lisboa: Gradiva - Cadernos Democráticos, 1999b.

12 CANOTILHO, J.J. Gomes. Estado de Direito. Lisboa: Gradiva - Cadernos Democráticos, 1999b.

13 CADEMARTORI, Sérgio. Estado de Direito e legitimidade: uma abordagem garantista. Porto Alegre, Livraria do Advogado, 1999. p. 20.

14 BEDIN, Gilmar Antonio. Estado, Direito e Justiça: em busca de um conceito de Estado de direito. In: Revista Direito em Debate. ljuí: Unijuí, n 16/17, 2002. p. 176.

15 BEDIN, Gilmar Antonio. Estado, Direito e Justiça: em busca de um conceito de Estado de direito. In: Revista Direito em Debate. ljuí: Unijuí, n 16/17, 2002. p. 178-179.

16 STRECK, Lênio Luiz; MORAIS, José Luís Bolzan de. Ciência Política e Teoria Geral do Estado. Porto Alegre, Livraria do Advogado, 2000. p. 87. 
Os democratas radicais entendem que o Estado deve intervir para corrigir os males e incertezas do mercado, embora não sejam a favor da socialização dos meios de produção. Já para os socialistas democráticos, o Estado deve atuar no domínio econômico, de forma a socializar os meios e produção.

18 STRECK, Lênio Luiz; MORAIS, José Luís Bolzan de. Ciência Política e Teoria Geral do Estado. Porto Alegre, Livraria do Advogado, 2000. p. 54.

19 Em um modelo liberal o Estado não interfere na saúde individual, por exemplo.

20 No modelo de Estado Social, o Estado adota políticas públicas voltadas à proteção dos direitos individuais e sociais, dentre eles, o direito à saúde.

21 MORAIS, José Luis Bolzan de. As Crises do Estado e de Constituição e a Transformação Espacial dos Direitos Humanos. Porto Alegre, Livraria do Advogado, 2002. p. 34.

22 WOLKMER, Antônio Carlos. Elementos para uma Crítica do Estado. Porto Alegre: Sérgio Antônio Fabris, 1990. p. 46.

23 "Ainda em algumas partes há povos e rebanhos; mas entre nós, irmãos, entre nós há Estados. Estados? Que é isso? Vamos! Abri os ouvidos, porque vos vou falar da morte dos povos. Estado chama-se o mais frio de todos os monstros. Mente também friamente, e eis que mentira rasteira sai da sua boca: 'Eu, o Estado, sou o povo'. É uma mentira! Os que criaram os povos e suspenderam sobre eles uma fé e um amor, esses eram criadores: serviram a vida. Os que armam ciladas ao maior número e chamam a isso um Estado são destruidores; suspendem sobre si uma espada e mil apetites. Onde há aina povo não se compreende o Estado, que é odiado como uma transgressão aos costumes e às leis. [...]" NIETZSCHE, Friedrich. Assim falou Zaratustra. São Paulo: Martin Claret, 2009. p. 55.

24 WOLKMER, Antônio Carlos. Elementos para uma Crítica do Estado. Porto Alegre: Sérgio Antônio Fabris, 1990. p. 50.

25 Apud STRECK, Lênio Luiz; MORAIS, José Luís Bolzan de. Ciência Política e Teoria Geral do Estado. Porto Alegre, Livraria do Advogado, 2000. p. 97.

26 STRECK, Lênio Luiz; MORAIS, José Luís Bolzan de. Ciência Política e Teoria Geral do Estado. Porto Alegre, Livraria do Advogado, 2000. p. 134.

27 Art. 6 CF. São direitos sociais a educação, a saúde, a alimentação, o trabalho, a moradia, o lazer, a segurança, a previdência social, a proteção à maternidade e à infância, a assistência aos desamparados, na forma desta Constituição.

28 LUHMAN, Niklas. Sociologia do Direito. Rio de Janeiro: Tempo Brasileiro, 1983.

29 SUSTEIN, Cass. The Partial Constitution. Cambridge: Harvard University Press, 1994.

30 VIANA, Luiz Werneck; CARVALHO, Maria Alice Rezende; MELO, Manoel Palácios Cunha; BURGOS, Marcelo Beummam. A judicialização da política e das relações sociais no Brasil. Rio de Janeiro: Revan, 1999.

31 SARLET, Ingo Wolfgang apud LEAL, Rogério Gesta. Condições e possibilidades eficaciais dos direitos fundamentais sociais: os desafios do Poder Judiciário no Brasil. Porto Alegre: Livraria do Advogado Editora, 2009. p. 150.

32 DWORKIN, Ronald. O império do Direito. Tradução de Jefferson Luiz Camargo. São Paulo: Martins Fontes, 1999.

33 LEAL, Rogério Gesta. Condições e possibilidades eficaciais dos direitos fundamentais sociais: os desafios do Poder Judiciário no Brasil. Porto Alegre: Livraria do Advogado Editora, 2009. p. 150.

34 DWORKIN, Ronald. Uma questão de princípio. Tradução de Luís Carlos Borges. São Paulo: Martins Fontes, 2001. p. 101.

35 LEAL, Rogério Gesta. Condições e possibilidades eficaciais dos direitos fundamentais sociais: os desafios do Poder Judiciário no Brasil. Porto Alegre: Livraria do Advogado Editora, 2009. p. 152.

36 CARNELUTTI, Francesco. Como Nasce o Direito. Tradução Ricardo Rodrigues Gamas, 1a edição. Campinas: Russel Editores, 2004. p. 60.

\section{REFERÊNCIAS}

BEDIN, Gilmar Antonio. Estado, Direito e Justiça: em busca de um conceito de Estado de direito. In: Revista Direito em Debate. ljuí: Unijuí, nº 16/17, 2002.

A Sociedade Internacional e o Século XXI: em busca da construção de uma ordem mundial justa e solidária. ljuí: Unijuí, 2001. 
BONAVIDES, Paulo. Do Estado Liberal ao Estado Social. 4. ed. Rio de Janeiro: Forense, 1980.

CADEMARTORI, Sérgio. Estado de Direito e legitimidade: uma abordagem garantista. Porto Alegre, Livraria do Advogado, 1999.

CANOTILHO, J.J. Gomes. Direito Constitucional e Teoria da Constituição. 3. ed. Coimbra, Portugal: Livraria Almedina, 1999a.

. Estado de Direito. Lisboa: Gradiva - Cadernos Democráticos, 1999b.

CARNELUTTI, Francesco. Como Nasce o Direito. Trad. Ricardo Rodrigues Gamas, 1a ed. Campinas: Russel Editores, 2004.

CORRÊA, Darcísio. A Construção da Cidadania - reflexões histórico-políticas. ljuí: Unijuí, 2000.

DWORKIN, Ronald. Uma questão de princípio. Traudução de Luís Carlos Borges. São Paulo: Martins Fontes, 2001.

Martins Fontes, 1999.

O império do Direito. Tradução de Jefferson Luiz Camargo. São Paulo,

LEAL, Rogério Gesta. Condições e possibilidades eficaciais dos direitos fundamentais sociais: os desafios do Poder Judiciário no Brasil. Porto Alegre: Livraria do Advogado Editora, 2009.

LUHMAN, Niklas. Sociologia do Direito. Rio de Janeiro: Tempo Brasileiro, 1983.

MORAIS, José Luis Bolzan de. As Crises do Estado e de Constituição e a Transformação Espacial dos Direitos Humanos. Porto Alegre: Livraria do Advogado, 2002.

NIETZSCHE, Friedrich. Assim falou Zaratustra. São Paulo: Martin Claret, 2009.

SARLET, Ingo Wolfgang. Algumas considerações em torno do conteúdo, eficácia e efetividade do direito à saúde na Constituição de 1988. Salvador: Revista Diálogo Jurídico no 10, jan. 2002.

SCHWARTZ, Germano (Org.). A saúde sob os cuidados do direito. Passo Fundo: UPF, 2003.

STRECK, Lênio Luiz; MORAIS, José Luis Bolzan de. Ciência Política e Teoria Geral do Estado. Porto Alegre: Livraria do Advogado, 2000.

A crise de efetividade do sistema processual brasileiro. In: Revista Direito em Debate. ljuí: Unijuí, 1995, nº 5. p. 64-75.

SUSTEIN, Cass. The Partial Constitution. Cambridge: Harvard University Press, 
1994.

WERNECK VIANA, Luiz; CARVALHO, Maria Alice Rezende; MELO, Manoel Palácios Cunha; BURGOS, Marcelo Beummam. A judicialização da política e das relações sociais no Brasil. Rio de Janeiro: Revan, 1999.

WOLKMER, Antônio Carlos. Elementos para uma Crítica do Estado. Porto Alegre: Sérgio Antônio Fabris, 1990.

Recebido para publicação: 16/11/2010

Aceito para publicação: 26/12/2010 